\title{
Statistics on the International Trade Administration's Global Markets Program*
}

\author{
by \\ C.J. Krizan \\ U.S. Census Bureau
}

\section{CES 15-17 September, 2015}

The research program of the Center for Economic Studies (CES) produces a wide range of economic analyses to improve the statistical programs of the U.S. Census Bureau. Many of these analyses take the form of CES research papers. The papers have not undergone the review accorded Census Bureau publications and no endorsement should be inferred. Any opinions and conclusions expressed herein are those of the author(s) and do not necessarily represent the views of the U.S. Census Bureau. All results have been reviewed to ensure that no confidential information is disclosed. Republication in whole or part must be cleared with the authors.

To obtain information about the series, see www.census.gov/ces or contact Fariha Kamal, Editor, Discussion Papers, U.S. Census Bureau, Center for Economic Studies 2K132B, 4600 Silver Hill Road, Washington, DC 20233, CES.Papers.List@census.gov. 


\begin{abstract}
Recent mandates for evidence-based policy choices from both the Executive and Legislative branches of the federal government underscore the importance of understanding the relationship between program participation and business outcomes. In this paper, we examine the correlations between participation in an export-promotion program and business outcomes. We use this experience to provide more general lessons learned about combining program data on treatments with Census Bureau micro data that can be used as a control. Note this paper does not evaluate a program, but instead provides critical information about a program.

The mission of the Commercial Service/Global Markets program is to help companies either start or increase their exports of goods and services. It pursues this mission through advocacy, events, and counseling. This study looks at a very small part of the overall program. While we cannot rule-out several sources of bias in our results, we do observe several consistent patterns across our models. In particular, program participation is positively correlated with export growth and change and, for small businesses, also with positive employment growth. However, overall, and for large firms in particular, there is a negative correlation with employment growth and counseling.
\end{abstract}

The paper concludes with a "Lessons Learned" section that highlights areas where measurement can be improved.

\footnotetext{
* Thanks to Nathan Goldshlag and Yana Morgoulas for their excellent research assistance work and to Randy Becker, Maksim Belenkiy, J. David Brown, Joe Carter, Elizabeth Clark, Debra Delay, Emin Dinlersoz, Mark Doms, Lucia Foster, Christine Heflin, Susan Helper, Cassandra Ingram, Ron Jarmin, Shawn Klimek, Harry Knight, Cynthia Nickerson, Julian Richards, Robert Rubinovitz, Cristina TelloTrillo, and James Tybout for their helpful comments and suggestions.
}

Contact:Cornell.J.Krizan@census.gov 


\section{Introduction}

The U.S. Department of Commerce's Commercial Service/Global Markets program (hereafter called GM) is part of the International Trade Administration (ITA). GM's mission is to assist and advocate for U.S. businesses in international markets to increase U.S. exports, and by extension, employment. ${ }^{1}$ To fulfil this mission, GM has offices across the United States and around the world in U.S. consulates and embassies to provide U.S. companies with services and information such as counseling, market research, commercial diplomacy, and matchmaking with foreign importers.

Similar agencies exist in many other countries and organizations. For example, Germany Trade and Invest describes itself as: “...the economic development agency of the Federal Republic of Germany. The organization promotes Germany as a business and technology location and supports companies based in Germany with global market information." 2 An outstanding question about these trade programs however is whether there is evidence of correlation between participation in such programs and changes in business performance. ${ }^{3}$

This question became increasingly important following a recent directive from the White House highlighting the need for evidenced-based policymaking that uses quantifiable metrics of how well programs meet their intended goals. In this way, successful programs can be nurtured and expanded while those that do not perform well can be reformed or eliminated. ${ }^{4}$ Similarly, a recent paper from the House Budget Committee also stressed the need for "results-driven research". 5

The goal of the research discussed below is not to evaluate the effectiveness of the GM program or to make any recommendations about changes to the program. Instead, I provide a broad range of statistics that describe the correlations between a small part of the overall program, export counseling to goods (not services) producers, and the businesses' export and employment growth. I do so by matching data on firms that received counselling from the GM program from 2002-2011 to longitudinal Census Bureau micro-level data on firm employment and export growth for the universe of goods-selling firms. The Census data allow me to control for both selection effects as well as for other important characteristics such as firm age and industry.

Other researchers have used Census firm-level data to compute program data statistics. Jarmin (1999) looked at the correlation between firms' participation in the National Institute of Standards and Technology's Manufacturing Extension Program (MEP) and their productivity and sales growth. The goal of the MEP is to help small- and medium-sized manufacturers grow and become more productive through providing business and technical assistance. Because, MEP program data and the Longitudinal Research Database (LRD) did not contain common numeric identifiers, Jarmin matched the two data sets

\footnotetext{
${ }^{1}$ http://www.trade.gov/markets/

${ }^{2}$ http://www.gtai.de/GTAI/Navigation/EN/invest.html

${ }^{3}$ Other examples of country-sponsored agencies include: the Australian Trade Commission, the Brazilian Trade and Investment Promotion Agency (apex-Brasil), the Canadian Trade Commissioner Service, the Korea TradeInvestment Promotion Agency, the International Enterprise Singapore, and the United Kingdom's Trade and Investment agency.

${ }^{4}$ http://www.whitehouse.gov/sites/default/files/omb/performance/chapter8-2012.pdf

${ }^{5}$ http://budget.house.gov/uploadedfiles/expanding_opportunity_in_america.pdf
} 
on name and address. He found evidence that MEP assistance is positively correlated with productivity growth but did not find a significant relationship with sales growth.

Following up on Jarmin's work, Ordowich et al. (2012) match more recent MEP data to the Census Bureau's Longitudinal Business Database (LBD). They use lagged dependent variable and difference-indifference (DID) techniques to look for correlations between participation in MEP programs and labor productivity. Overall the two models produced differing results and they were unable to draw firm conclusions about the existence or direction of the relationship between firm productivity growth and program participation. However, they did find positive and significant coefficients on program participation for small firms.

A related study was also recently published by the National Academies in which these same authors compared the MEP program to similar programs in other countries. ${ }^{6}$ They sought to identify foreign practices that the MEP could adopt as well as to compare funding levels and outcomes across programs/nations. They found that MEP is a relatively low-cost program with evidence of producing results. Many countries sponsor technology adoption programs. The most successful ones have longterm stable funding, are staffed with well-qualified experts, operate with high levels of independence and have strong ties to local industry clusters. Most recently, Lipscomb et al. (2015) found some evidence that MEP services had positive effects on productivity and sales while increasing the probability of establishment survival.

Finally, Small Business Administration (SBA) loan programs were the focus of work by Brown and Earle (2013). In the programs that Brown and Earle studied, the SBA provides loan guarantees to small businesses that may otherwise not be able to obtain funding. Their goal is to foster business growth. Brown and Earle use both fixed effects and matching models and find evidence of a strong correlation between program participation and employment growth of the firm.

\section{Data}

\section{A) GM Data}

The GM data are for the years 2002-2011 and are maintained in two main files. There is an underlying "Organization” file that records the basic contact information for the firm. That is, each time the agency has any type of contact with the firm, whether it's an e-mail or a full-blown counseling session, they record the firm's information, but not the date of the interaction. Firms are typically contacted multiple times by GM, often by different people, and each time the contact is recorded, the client firm is identified by its name. No numeric identifiers are assigned to firms, although there is a unique identifier for the interaction. Because the firm's name is hand-entered multiple times by different people, variations in spelling are inevitable. This makes it very difficult to consistently identify a firm in the database or to measure fully the treatment it receives. This is an important issue because failure to account for all GM interactions with the treated firms will bias our results upward (under the null hypothesis of no effect). That is, assuming that counseling has a positive effect, by under-counting the number of counseling

\footnotetext{
${ }^{6}$ http://www.nap.edu/catalog/18448/21st-century-manufacturing-the-role-of-the-manufacturing-extension-
} partnership 
sessions that are associated with a given change in performance, I may over-estimate the true effect of GM services on their client firms.

In order to consistently identify the various firms in the data and accurately measure the counseling they receive, I use the Web site and e-mail addresses provided by the client firms to create a new, consistent firm identifier. ${ }^{7}$ Specifically, I use name and address matching software tools to strip-off the leading prefix and domain names to keep the core name of the site. For example, the Web sites "www.joeswidgets.com”, “joeswidgets.com”, and "http://joeswidgets.biz” each yield the firm identifier “joeswidgets”. Similarly, bob@joeswidgets.com and mary@joeswidgets.com also yield the identifier “joeswidgets”. I use Web site data whenever possible but default to e-mail addresses if Web site data are not available. I also exclude e-mail addresses from large, mass e-mail providers such as Google or Yahoo. I are unaware of any other papers that use this information as a firm identifier or for record linkage purposes.

Although they are somewhat novel and unconventional, I believe that Web-based firm identifiers have several advantages. For example, a person inputting the information into the database is less likely to introduce variations into a Web site address than they are for firm name. And, as the examples above show, my methodology is robust to the most likely variations I expect to appear in spelling and format. Another advantage of using Web addresses is that they are major assets for the firms and are unlikely to change over time. That is, firms expend a great deal of effort to make their sites well-known and visited and would think carefully before changing their address. Finally, a complex conglomerate will likely have several distinct sites, one for each major brand/activity and the sites would be unlikely to change in the event of a merger/acquisition. If true (and this is a matter for further research), this means that the Web-based firm identifier is likely to define a firm as a sub-entity of a conglomerate with a distinct business niche.

As shown below, I was able to construct firm identifiers (GM_IDS) for approximately 85\% of the interactions in the organization database. In separate results, I also estimated that the GM_IDs have about a $90 \%$ accuracy rate. ${ }^{8}$ That is, about $85 \%$ of the observations had GM_IDs and 90\% of the GM_IDs looked accurate.

In addition to the "Organization" file, there is also a separate "Interactions" file which records the more significant interactions between GM and the firm. These data include the date of the interaction as well as a flag for whether or not the interaction is significant enough to be judged as "counseling” by the GM employee. This may be a biased measure of whether or not the session is truly counseling. Employees may, depending on the incentive structure under which they are working, have an incentive to record only interactions that they believe are likely to have a positive outcome. I use this flag as a measure of the counseling the firm receives but acknowledge that it may bias results towards finding evidence of a treatment effect.

\footnotetext{
${ }_{8}^{7}$ See Appendix 1 for details.

${ }^{8}$ These results come fromrandomly selecting a sample of 100 GM_IDs and checking their raw data on Web and firm name and address together with the firm identifiers I constructed to see if they seemed to accurately reflect the same firm over time.
} 


\section{B) Census Data}

The data used for the matching come from the Census Bureau's Business Register (BR) files, and the firm data for treated and non-treated firms come from the LBD and the Longitudinal Foreign Trade Transactions Database (LFTTD). The BR is Census' business sample frame and contains data on all nonfarm businesses with paid employees in the United States. It also includes business name and address as well as a numeric identifier that can be linked to the LBD. The LBD was developed by Jarmin and Miranda (2002) and covers all establishments and firms in the non-farm business sector from 1976 to 2012 and includes information about employment, detailed location, detailed industry and ownership structure. There are roughly 8 million establishment records per year.

Since the GM counseling information is at the firm-level, I aggregate the establishment data to the firm level. Doing so is not entirely straightforward. For example, in cases where firms operate establishments in multiple industries, I choose the industry with the greatest employment as the firm's sector. A more complex issue involves firm births, mergers, and acquisitions. For example, consider a new firm identifier that appears in 2004 that is comprised entirely of continuing establishments. As Haltiwanger, Jarmin and Miranda (HJM) note, this is not necessarily a good definition of a firm birth. It is more likely the product of merger and acquisitions (M\&A) activity. I follow HJM and define a firm birth as a new BR_ID (Business Register ID) with all new establishments attached to it. Otherwise, if a firm identifier disappears but its establishments continue under two different firm identifiers the following year, I allocate the employment change of the establishments to their respective new firm identifiers.

The LFTTD links individual trade transactions (both import and export) to firms operating in the United States between 1992 and 2011. I focus exclusively on export flows in this paper. Each export transaction record provides information on: (i) the ten-digit Harmonized System (HS) classification of the product which I aggregate to the two-digit HS level; henceforth, the term "product” will refer to two-digit HS; (ii) nominal values that I convert to real terms using the annual Consumer Price Index (CPI); (iii) destination country; (iv) the transaction date which I aggregate to the annual level; (v) whether the transaction takes place between related parties or at arm's length; and (vi) the identity of the exporting firm.

The LBD and LFTTD are merged on their common numeric firm identifier. Although the GM program also targets service-providing exporters, the LFTTD covers only goods. Thus, I restrict the sample to manufacturing, wholesale and retail firms operating during the period covered by the GM data: 20022011.

\section{C) Matching}

Since the Census and GM datasets do not contain a common numeric identifier (e.g., Employer Identification Number, or DUNS number), I linked them on their name and address fields. Matching is accomplished by using probabilistic name and address matching to the BR file. The matches are then linked to the LBD via a numeric firm identifier common to both data sets.

Probabilistic name and address matching goes through four main matching categories. Each category includes a name, but the address criterion is loosened across matching passes to accommodate differences in reporting from different sources as well as moves by businesses to new addresses. The first round is 
name and address. The second round is name and zip code. The third round is name and city. The final round is name and state.

Fifty-nine matching passes among the four main matching categories are implemented. Passes incorporate variations on the name category, which range from exact, to abbreviated, and then a probabilistic version of business name. Passes also incorporate variations within each address category. Passes include probabilistic versions of the full street address and truncated street address as well as full zip code and truncated zip code. Matches that count the number of overlapping words between the GM business name and the Census business register name are also incorporated in each of the main matching categories. When the number of overlapping words exceeds the threshold, a match is established. This method is helpful when the owners use long and short variations on the same business name.

All GM observations are matched to all years of the Census BR from 2002 to 2011. The strategy used in this study of matching GM data to all years of the BR is employed to increase the likelihood of a match. Once linked to the BR, the data could then be linked to the LBD, which is the source for longitudinal and firm characteristic information. At the time of this study, the LBD was available through 2011, so any firms starting after that year could not be linked or analyzed.

I performed the probabilistic match between the 227,782 contact records in the Organization files and the BR via SAS DQMATCH. I achieve an overall match rate of $64 \%$, including duplicate matches. ${ }^{9}$ Recall also that only $85 \%$ of the GM Organization records have a GM_ID. This further reduces the absolute match rate to $54.4 \%$ of the organization records. Once I remove the duplicate matches, impose restrictions that there are valid firm identifiers in both datasets, impose industry restrictions, and aggregate establishments to the firm level, I am left with a sample of about 17,000 unique GM firms (about 15,500 of which are on record as having been counseled at least once) and about 2.25 million firms in the universe of goods-producers and traders. ${ }^{10}$

Because this is smaller than the number of Interactions (not firms) in the original data it is worthwhile to ask how the final data compare to the initial sample and to the rest of the business universe. Appendix 2 examines the match in detail. As is typically the case, the match rate to smaller, younger firms was lower than average (Table A2-4). However, I do not observe any systematic differences in our matches compared to the base sample.

Similarly, Table 1 reports the means of the matched GM sample compared to the universe of manufacturing, wholesale and retail trade firms from the LBD. ${ }^{11}$ Several interesting differences emerge. GM firms are more likely to be multinational corporations (MNCs). They are also larger and older than average. They are, on average, 15 years old at the time they first receive counseling from the GM program, indicating that they are at a fairly mature stage of development when they begin to investigate the possibility of exporting goods. GM firms also are disproportionately represented in the manufacturing sector.

\footnotetext{
${ }^{9}$ That is when a single firm from one data source matches to multiple firms in the other.

${ }^{10}$ These operate in Manufacturing (NAICS 31-33), Wholesale (NAICS 42), and Retail Trade (NAICS 44-45).

${ }^{11}$ Note that the previously discussed lower match rate for smaller firms biases the results slightly towards larger firms.
} 


\section{Methodology}

\section{A) Background}

\section{Program Participation Issues}

To purely assess whether GM counseling services has an effect on firm performance, or what would have happened to GM assisted businesses in the absence of the program (the "counterfactual"), is impossible as one cannot go back in time. However, there are methods that can be used that allow for reliable assessments of program effects. Many of these methods rely on developing a group of businesses that did not receive assistance as a comparison group (the "control” group). The preferred method would be to use a randomized controlled trial to create the comparison group, but randomly assigning who receives or does not receive assistance is not always possible in program delivery, especially if it is a retrospective analysis.

The next best alternative is to look for effects of counseling while controlling for all other factors relevant to performance. This is very difficult to do. I must control for general firm characteristics such as industry, size, and age. Additionally, I must recognize that firms receiving counseling may differ systematically from non-treated firms in ways that these standard variables may not capture. For example, it may be that only more competent, motivated firms seek out aide from GM. Alternatively, it may be that the firms most likely to get assistance are those experiencing hardship and/or in need of new replacement markets for their goods. That is, it may be that firms going through some sort of difficult period (e.g., loss of domestic market share) are looking for a way to improve their performance. This is the well-known issue of selection bias. Below, I use several different models to attempt to control for this bias and look for cases of general agreement. These instances of agreement will constitute the strongest evidence of true correlation.

Another issue that must be considered is that firms being treated by GM may participate in more than one program. For example, firms in the GM program may be receiving aide from other government agencies such as the Small Business Administration (SBA). This can affect the accuracy of our results if I falsely ascribe changes in performance to participation in the GM program, when in fact it is the SBA program that prompts the change.

Unfortunately, I have no clear way to control for participation in other programs and couch the results accordingly. I return to this issue in the "Lessons Learned" section at the conclusion of the paper. Ideally, one would want data collected on business assistance by various government agencies to be housed in a central location such as the Census Bureau and to share a common firm identifier (such as an Employer Identification Number or Web site address) and common data definitions.

Another generic issue in calculating program-level statistics is that I may under-estimate the effects of counseling if there are substantial spillover effects across firms. That is, if firms participating in GM programs are able to pass along their know ledge of exporting to nearby firms, I will systematically underestimate the correlation between GM and changes in firms' exporting behavior.

Finally, as noted above, I may not be fully capturing all the interactions that GM has with its client firms. In addition to unrecorded counseling sessions, some firms may also purchase matching services from GM 
that pairs them with a potential importer in a foreign market. Failure to account for these additional services biases the results towards finding an effect from counseling.

\section{Exporting Issues}

There are also several important potential sources of bias arising when measuring changes in exports. The exporting literature has documented a great deal of firm heterogeneity and hysteresis among exporters (Roberts and Tybout 1997). The intuition from these models is that there are substantial fixed costs to becoming an exporter. Because of this, firms' past decisions play a large role in their current decision about exporting. Current exporters face only a small additional cost if they decide to export next period. That is, they are much more likely to export next period than current non-exporters, even when it may not be profitable to do so. They do this in order to avoid having to re-pay the fixed cost. If firms in this position are more or less likely to request counseling from GM, the results will be biased.

Another important consideration is the potential simultaneity between the decision to export (or expand employment) and the decision to seek counseling from GM. In many cases, a firm may decide to export and also seek counseling because of some exogenous factor that I cannot observe. If, for example, the owners of a small firm make a social connection with a potential buyer while on vacation overseas, they may decide simultaneously to become exporters and seek counseling to learn how to go about it. However, I will only observe the increase in exports and attribute it to GM counseling. Again, while I acknowledge this potential bias, it is beyond the scope of the current work to address it.

Firms also differ in their expectations about future market conditions and demand for their product, which affects their willingness to pay the fixed export cost. Programs or policies designed to promote exports will produce different effects depending on the client firms' distribution of future expectations. These considerations mean that the decision to export is quite complicated. It is typically estimated with discrete choice, dynamic models featuring firm heterogeneity (Das Roberts and Tybout 2007). These are very complicated models to build and estimate and, because of limited resources, are unfortunately beyond the scope of this paper. However, the program data will remain available to outside researchers in the Federal Statistical Research Data Centers (FSRDCs). In this work, I acknowledge that I am not fully addressing all potential exporter issues and that the results may therefore be biased in an uncertain direction.

\section{Exporting and Employment Growth}

It is well known that many jobs are dependent on exports (Tschetter 2010). However, the connection between exporting, employment, and productivity grow th at the firm-level is less clear-cut. The decision to export is complex and involves the payment of substantial sunk costs (Roberts and Tybout 1997; Das, Roberts, and Tybout 2007). These sunk costs may be paid because exporting firms are already larger and more productive than other firms (Bernard and Jensen 1999; Melitz 2003). However, there is little evidence to suggest that firms become more productive because of exporting. Instead, the aggregate productivity growth from exporting comes through re-allocation of activity to more productive exporting firms (Bernard, Jensen, Redding and Schott 2007; Melitz 2003).

Furthermore, there is a great deal of entry and exit from exporting, despite the high sunk costs; up to half of exporters do so only once (Eaton, Eslava, Kugler, and Tybout 2008; Bernard, Jensen, Redding, and 
Schott 2009) and much of the costs of becoming a successful exporter are connected to building successful networks of foreign buyers (Eaton, Eslava, Jinkins, Krizan, and Tybout 2015). Given this intense volatility and heterogeneity among exporting firms, it is not surprising that the employment and shipment grow th benefits from exporting observed in the data accrue largely to a few continuing, highly successful exporters (Bernard and Jensen 1999; Das, Roberts, and Tybout 2007).

It seems likely that the effects of exporting on firm employment could vary, particularly in the short run. All things equal, more demand is expected to lead to using more inputs, including labor. However, it is also possible that a firm's first exposure to intense international competition could lead to capitalintensive changes in its production technology that may lead to employment cuts in the short or medium term. Another factor to consider is that firms that diversify their demand across countries may be less vulnerable to shocks, unless the foreign markets are more volatile than the domestic market (Kurz and Senses 2013; Vannoorenberghe 2012). In fact, recent empirical work finds that U.S. exporters' employment is $3-7 \%$ less volatile than non-trading firms, although these results also largely accrue to firms with well-established export markets that rely on these markets for $17 \%$ or more of their total revenue (Kurz and Senses 2013).

\section{Multinational Corporations (MNCs)}

A final important exporter-related consideration is the presence of an unknown but non-trivial share of unidentified MNCs in the GM sample. ${ }^{12}$ It is well known (Bernard, Jensen, and Schott 2009) that MNCs have higher levels of export and employment growth and are more likely to survive than other firms. To address this issue, I follow Bernard, Jensen, and Schott (2009) and make use of the "related party trade" flag in the LFTTD to identify the MNCs in these data. ${ }^{13}$ I add this variable as a control in our models but acknowledge that it is an imperfect measure of the MNC universe in these data.

\section{B) Implementation}

As mentioned above, our methodology owes much to Jarmin (1999). Like Jarmin, I acknowledge that the simplest Ordinary Least Squares (OLS) specifications of our model are almost certainly biased, but these simplest results provide a useful starting point for more sophisticated modeling work in the future and thus serves as a benchmark for those results.

\section{OLS \& Fixed Effects}

Here, the core specification is

$\mathrm{Y}_{\mathrm{it}}=\beta_{0}+\beta_{1}$ Age_cat ${ }_{\mathrm{it}}+\beta_{2} \mathrm{MNC}_{\mathrm{it}}+\beta_{3}$ Sector $_{\mathrm{it}}+\beta_{4}$ Year $_{\mathrm{it}}+\beta_{5}$ Counseling $_{\mathrm{it}}+\varepsilon_{\mathrm{it}}$

where "i" = firm, "t" = year, and

\footnotetext{
${ }^{12}$ I am aware of their existence both through close examination of the firm names and other variables in the data, as well as from extensive conversations with GM staff members.

${ }^{13}$ These authors note that: "Related party" traderefers to trade between U.S. companies and their foreign subsidiaries, as well as trade between U.S. subsidiaries of foreign companies and their foreign affiliates. For imports, firms are related if either owns, controls, or holds voting power equivalent to 6 percent of the outstanding voting stock or shares of the other organization (see Section 402[e] of the Tariff Act of 1930). For exports, firms are related if either party owns, directly or indirectly, 10 percent or more of the other party (see Section 30.7[v] of the Foreign Trade Statistics Regulations).
} 
$\mathrm{Y}=$ Firm performance (discussed below)

Age_cat $=$ A set of firm age dummies

$\mathrm{MNC}=$ A dummy variable for MNC status

Sector = Identifies the firms’ industry (Manufacturing, Wholesale, or Retail Trade)

Year $=$ A dummy variable for the year of observation

Counseling = A measure of the counseling received by the firm (discussed below)

This panel data OLS model has the advantage of being simple to estimate and easy to interpret. Although subject to selection bias, it serves as a useful initial estimate of the effects of GM counseling. Therefore, like Jarmin (1999), our next step is to add firm fixed-effects and re-estimate the model. This specification is also simple to interpret and it controls for any unchanging attributes of the firm (e.g., managerial ability) that may be correlated with the firm's decision to get counseling from the GM program.

Throughout the paper our measures of firm performance include percent growth in exports and employment. To avoid entry/exit issues when measuring growth rates, I adopt the Davis, Haltiwanger and Schuh (1996) growth rate measure that uses the average of the two periods ( $\mathrm{t}-1$ and $\mathrm{t}$ ) as the denominator. This method produces percent change measures roughly similar to those obtained from log differences but can be computed when there is a zero in one of the two time periods.

Whenever possible I use three measures of counseling: a count of contemporaneous counseling sessions ("counseling”), the total number of counseling sessions from t-2 to t (total counseling or "tc"), and a dummy variable that equals one if tc $>0$.

\section{Two-Stage Model (Maddala (1983))}

Next, I estimate a version of Maddala's (1983) 2-stage model, also used by Jarmin (1996). Its general form is:

$\mathrm{Y}_{\mathrm{cit}}=\beta \mathrm{X}_{\mathrm{cit}}+\mu_{\mathrm{cit}}$

$\mathrm{Y}_{\mathrm{ncit}}=\beta \mathrm{X}_{\mathrm{ncit}}+\mu_{\mathrm{ncit}}$

$\mathrm{GM}_{\mathrm{it}}^{*}=\mathrm{Z}_{\mathrm{it}} \gamma+\varepsilon_{\mathrm{it}}$

Where $c$ denotes clients and $n c$ flags non-client firms. While Jarmin's measure of program treatment was binary, I have data on the number of counseling sessions firms receive. I will make greater use of this information in subsequent specifications but for this model I consider a firm to be a client in year $t$ if it received counseling between $\mathrm{t}-2$ and $\mathrm{t}(\mathrm{tc}>0) . \mathrm{GM}_{\mathrm{it}}{ }^{*}$ is the estimated likelihood of receiving treatment using the variables in $\mathrm{Z}_{\mathrm{it}}$, which includes all the variables in $\mathrm{X}_{\mathrm{it}}$ as well as a measure of the distance from the firm to the nearest GM office as an identifying instrument. ${ }^{14}$

\footnotetext{
${ }^{14}$ In the case of multi-unit firms, I use the average distance fromits establishments to the nearest GM offices.
} 
As Jarmin (1996) notes, this model allows separate coefficients for clients and non-client firms while accounting for the potential covariance between $\mu_{\mathrm{cit}}$, $\mu_{\text {ncit }}$ and the error term $\varepsilon_{\mathrm{it}}$ in (4). Such a relationship will bias the OLS estimates from (1). Jarmin estimates these models both separately and pooled together. For reasons of tractability, I only estimate the pooled model. ${ }^{15}$

Finally, I also note that, as discussed in Lee (1982), OLS produces consistent estimates of the coefficients and inconsistent estimates of the standard errors in the second stage of the regression. I correct the standard errors following the procedures outlined in Lee (1982) and White (1980).

\section{Results}

\section{A) OLS Regressions}

As mentioned above, the OLS regressions allow one to control for observable firm characteristics - but not for selection effects. Nonetheless, they serve as a useful benchmark for the rest of the regressions. The OLS coefficients and standard errors are presented in Table $2 .{ }^{16}$ The results are ordered according to the measure of firm performance used as the dependent variable and include separate rows for each of the three measures of counseling. Overall, there are positive and significant correlations between all the measures of counseling with export and employment growth.

Given GM's mandate to aide small and medium sized companies (relative to other exporters), I also divide the firms into categories according to whether they have more or fewer than 500 employees, the definition of a small or medium-sized firm (relative to a larger firm) developed by the Small Business Administration and also used by the GM program. According to these results (Table 3), GM counseling is more strongly and positively correlated with business performance metrics for businesses of 500 or fewer employees. Only one of the coefficients for large firms is statistically significant while all the small firm estimates are significant.

\section{B) Fixed Effects}

While the OLS regressions control for a large number of firm characteristics, they do not control for unobservable fixed effects associated with the firm, including factors that may be related to selection effects. For example, managerial capability may be either positively or negatively associated with the likelihood of obtaining counseling. That is, it could be that only the most capable managers are able to seek out the GM programs and successfully implement them or it could be that lower-skilled managers are more likely to solicit outside help to enter the export market. Either way, the fixed effects regressions will control for these unchanging correlations between skill and treatment.

\footnotetext{
${ }^{15}$ To obtain the measure of the treatment effect fromthe separateregressions, Jarmin takes the differences in predicted values at themeans for the treated and untreated groups. It is not obvious that this is the correct approach here since all of the independent variables are categorical.

${ }^{16}$ The complete set of coefficients and standard errors for these and all other models, including the preliminary stages of the Heckman models, are provided in Appendix3.
} 
After controlling for firm fixed effects (Table 4), none of the employment growth coefficients are statistically significant (though the results for the yes/no measure are close). How ever, all three measures remain significant when export growth is the dependent variable.

\section{C) $\underline{\text { Pooled 2-stage model }}$}

Although the fixed effects models mitigate some of the selection bias, a more rigorous way to control for it is by using the two-stage model described in equations (2) and (3). The first stage of this Heckmanstyle model estimates the inverse Mill's ratio from a probit equation that estimates the likelihood of receiving counseling between t-2 and t. Following Jarmin (1996), the probit model includes all of the independent variables used in stage 2 as well as a measure of the distance from the firm to the nearest GM office.

The average distance to a GM office is about 33.4 miles for client firms and 39.1 for non-clients and a Ttest rejects the null hypothesis that they are equal. The first stage regression results, displayed in Table A3-1 of Appendix 3, show that the coefficient for distance is highly significant and negative. Our prior expectation was that firms farther from a GM office would be less likely to receive counseling. The negative and significant coefficient on the distance variable is in line with this expectation and provides evidence that distance is not an unreasonable instrument.

The counseling coefficients and corrected standard errors (Lee 1982; White 1980) from the second stage regressions are displayed in Table 5 and the full set of coefficients is displayed in Table A3-2 of Appendix 3. The patterns here are very similar to those observed in the simple OLS models. There is a positive and significant relationship between receiving counseling and employment and export growth.

\section{Summary of Empirical Findings}

Before summarizing the results, I again note that this study looked at only a small part of the overall GM program (counseling to goods producers and traders) and did not address several important metrics of firm performance such as firm survival or the duration of export relationships.

Several patterns emerged from the models. Almost all of the models find a statistically significant, positive correlation between GM program participation and export growth, particularly for small firms. Recall however that none of these models address hysteresis, simultaneity bias, or market expectations. Nor can I be certain that our measures of counseling are fully accurate or that I have accounted for all services provided by GM to the client firms. As such, I cannot rule out the possibility that the positive effects found in the models are simply reflecting these biases, although the consistency across them seems promising.

As discussed above, the connection between exporting and employment growth the firm-level is not straightforward and our employment growth results were not as uniform as those for export growth. While all of the models report positive coefficients, only some results are statistically significant. Neither 
the fixed effects or large-firm OLS results were statistically signific ant, although the coefficients from the other models were.

Finally, I note that the two-stage results require that the distance measure affects the likelihood of participation while not affecting how well the services are provided. The statistical significance and sign of the distance coefficients in the first stage of these models suggest it does play a role in the likelihood of entering the GM program. How ever, I cannot rule out that it also plays a role in how well the services are provided. That is, it may be that firms that are closer to the office get better forms of counseling (inperson) than those further away.

\section{Lessons Learned}

This section outlines important lessons learned from this analysis of the GM program and is intended to help guide the improvement of future similar analyses. As such, this is a case study example that feeds into larger interagency efforts to encourage and facilitate such analyses. For example, the interagency Evaluation of Business Trade Assistance Programs (E-BTAP) Working Group is developing a guide that outlines best practices.

\section{A) Importance of Unique Identifiers}

In general, the ability to use program data from Department of Commerce agencies is limited by the lack of common firm identification variables and unified data definitions. These gaps make it difficult to link and compare data across agencies. With a common set of core definitions such as firm identification and employment, the data could be centralized and a rich variety of questions could be investigated more easily. For example, it would be useful to know how many unique firms are being serviced by the various agencies. Similarly, it is important to know when/if a firm is getting help from multiple agencies, for program administration impact evaluation purposes.

The Census Bureau is uniquely well-situated to store and link data from multiple agencies. It has both data-linking expertise and the BR, which can be used for obtaining control groups as well as for measuring changes in firm performance. This study has discussed the difficulties I faced in linking data across agencies without a common identifier, especially when one source has no unique, permanent, firm identification variable, which may often be the case for programs collecting data on relatively small

numbers of firms from geographically diverse sources. It would be helpful for program agencies to decide collectively to adopt one or more standardized firm identifiers from the list below.

\section{Employer Identification Numbers}

Employer Identification Numbers (EINs) are a promising candidate as a universal firm identifier. Using EINs as a firm identifier has several advantages:

- Accuracy: EINs are numeric and therefore more accurate for matching purposes than firm name.

- Coverage: All employer firms, all exporters and importers, and many firms without employees such as partnerships and S Corporations have them.

- Constancy: They are likely to be constant over time. 


\section{EINs also have drawbacks:}

- Firms can apply for an unlimited number of EINs at no cost beyond the time needed to fill out the application.

o Many firms, particularly large multi-unit businesses, have multiple EINs and may not report the same number to different agencies.

- Firms may consider them to be private information and be reluctant to share them with government agencies since they are tax identifiers.

o EINs are tax data. Increased security costs may be required once the program data are comingled with them.

If a single firm reports different EINs to two different agencies, the agencies will not be able to use EINs to discern that they are dealing with the same firm. Even the Census Bureau, with its multi-decade long data on the universes of businesses has an incomplete list of all EINs in use by firms. This was demonstrated during the recent construction of the LFTTD. As documented by Bernard, Jensen, and Schott (2009), depending on the year of the data, roughly 18-28\% of the EINs reported during foreign trade transactions cannot be matched to the BR. Much lower match rates could be expected when two agencies attempt to link the data from their two samples without the help of the BR.

\section{Web Domain Names}

This study also demonstrated the usefulness of a novel new form of firm identification, the Web site or email address of the business. ${ }^{17}$ A Web address, like a physical address, defines the firm's location in (internet) space and has several advantages as a firm identifier.

\section{Web sites and e-mail addresses can be a useful alternative to EINS as an ID:}

- The vast majority of firms have and maintain a unique Web site and associated e-mail addresses.

- Firms expend a great deal of effort to make people aw are of their sites. They are substantial assets. The more constant they are over time the more useful they are so firms are unlikely to change them.

- Web addresses are public information and do not need to be kept in a secure environment.

- Unlike firm name and address information, different employees at the firm are likely to report the same Web address and to do so accurately. ${ }^{18}$

o Misspellings seem unlikely.

o Similarly, they are very likely to report accurately their own e-mail address.

- Web sites allow firms to self-identify and organize. For example, a large conglomerate is likely to give its various entities their own Web sites which may remain constant even in the presence of merger and acquisition activity.

\section{Name and Address}

\footnotetext{
${ }^{17}$ I exclude e-mail addresses with domain names clearly associated with large-scale e-mail providers.

${ }^{18}$ With the possible exception of leading/trailing information ("http”, “www", “.com”) which can be easily strippedoff with name and address matching software. A detailed example of how it can be used, based on the work done in this study, is in Appendix1.
} 
In the absence of other identifying information, this study, like others before it, used name and address information to link the data from the two agencies. It would be very beneficial for future studies if agencies collected this information. Agencies typically strive for match rates of roughly $70 \%$ (Jarmin 1996). Although it is a far from perfect means of linking data, it does allow some cross-agency matching. ${ }^{19}$ It could also be useful when used in conjunction with numeric identifiers such as EINs and may improve their usefulness.

Including some additional information about the firm greatly enhances the quantity and quality of the name and address matches. Key fields include NAICS code, employment (ideally measured as of March 12th of each year, to match Census’ definition), year of contact/treatment, and firm age.

\section{B) Treatment and Control Variables}

\section{Treatment}

Accurate statistics on the correlations between treatment and outcomes can only be calculated with reliable information on the time and intensity of the treatment received. For example, the GM program kept records on when counseling was performed, but there is some concern that contacts between the agency and client firms were considered to be counseling only when the person communicating with the business expected a positive outcome. This is an additional source of bias in the results.

Ideally, the treatment measure would record:

- Categorical descriptions of service/assistance provided (technical, access to credit, etc.)

- Date and duration of assistance

- Categorical type of interaction (email, phone call, office visit, workshop training, etc.)

- Measure of the intensity for each type of assistance/service provided (\# hours, fee charged, etc.)

\section{Information on Unassisted/Not-Treated Firms}

There may be instances where a firm applies for assistance but does not receive assistance. Information on such firms, together with an explanation (and/or any available objective measure such as firm age, size, etc.) of when they applied and why they did not get treatment, may be helpful in constructing a control sample.

Some baseline information should be collected on all firms that contact the agency:

- Firm name, address and identification (Web site, EIN)

- Industry

- Age

- Reason for contact

- Date of contact

\footnotetext{
${ }^{19}$ If addresses were standardized in some way, perhaps by being able to be found in common maps and driving direction Web sites, match rates may improve.
} 
- Program eligibility Why/Why not? (Also include any scoring that may have been used to make decisions on whether assistance was provided.)

C) Technical Issues

\section{Legal/Policy}

Agencies must ensure that they have all appropriate legal and policy approvals required for the use of their data in the manner described above. Any legal restrictions on the data should be identified and addressed before any other action is taken. The steps involved in conducting a study are (roughly):

- The program agency obtains legal clearance to merge its data with Census, with the understanding that the data will be kept confidential and any results released will be subject to strict disclosure avoidance rules.

o The Center for Economic Studies (CES) encourages agencies to allow the data to be made available to outside researchers at the FSRDCs. All projects would be reviewed and approved by CES and IRS and be conducted under strict security requirements. Such studies may improve the agency's understanding of the outcomes related to its program.

- A standardized reimbursable agreement is signed between the agencies.

- The program data are documented and transferred securely (and includes a Data Transfer Agreement).

- The data are matched to the BR and/or the LBD. Based on match rates and other considerations a decision is reached about the feasibility of calculating relevant statistics.

- If the decision is made to proceed, a research plan and timetable is developed by Census.

o The plan must be approved by the IRS. All projects must help Census learn more about the BR and/or improve it in some way.

o The research plan is also reviewed by non-participating Census researchers for viability and completeness.

- Once IRS and Census approval is obtained, the research proceeds.

- When the project is completed a CES Working Paper detailing the methodology and results of the study is published. Simultaneously, an internal document describing what was learned about the BR or how it was improved during the study is also written.

- If desired, Census will conduct a seminar/briefing for the agency detailing the findings of the study and the lessons that were learned about the program and/or its data.

\section{Data}

Important data considerations when beginning a project include:

- How will the data be transferred?

- Will it be encrypted? If so, will the other agency be able to un-encrypt it?

- When will the data be ready?

- What format is it in?

- Will all files come at the same time? 
- Do the data contain any non-standard characters (accent marks, letters from non-English alphabets) that may be unrecognized by SAS? E.g., were they entered on a keyboard overseas?

- Can a data dictionary be supplied to the receiving agency?

- Is all relevant background information on how the data were collected documented?

- Can the results of quality control tests be shared with the receiving agency?

In sum, this analysis of the GM program demonstrates that it is possible to provide an informative analysis of a business assistance program by linking program data to Census Bureau micro-level data, and further, future analyses could be improved by taking specific steps. 


\section{REFERENCES}

Bernard, A.J. and Jensen, J.B. (1999a). “Exceptional Exporter Performance: Cause, Effect, or Both?” Journal of International Economics, 47(1), 1-25.

Bernard, A.J. and Jensen, J.B. (1999b). “Exporting and Productivity,” NBER Working Paper No. 7135.

Bernard, A.J., Jensen, J.B., Redding, S.J., Schott, P.K., (2007). “Firms in International Trade.” Journal of Economic Perspectives, 21(3), 105-130.

Bernard, A.J., Jensen, J.B., and Schott, P.K., (2009). "Importers, Exporters and Multinationals: A Portrait of Firms in the U.S. that Trade Goods,” in T. Dunne, J.B. Jensen, M.J. Roberts, eds., Producer Dynamics: New Evidence from Micro Data, University of Chicago Press.

Bernard, A.J, Jensen, J.B., Redding, S.J., and Schott, P.K., (2009). “The Margins of US Trade,” American Economic Review, 99(2), 487-93.

Brown, J. D. and Earle, J.S., (2013). “Do SBA Loans Create Jobs?,” IZA Discussion Papers 7544.

Das, S., Roberts, M.J., and Tybout, J.R., (2007). "Market Entry Costs, Producer Heterogeneity, and Export Dynamics,” Econometrica, 75(3), 837-873.

Davis, S., Haltiwanger, J., Schuh, S., (1996). Job Creation and Destruction, Cambridge, MA: MIT Press.

Eaton, J., Eslava, M., Jinkins, D., Krizan, C.J. and Tybout, J.R., (2015). “A Search and Learning Model of Export Dynamics,” mimeo.

Eaton, J., Eslava, M., Kugler, M. and Tybout, J.R., (2008). “Export Dynamics in Colombia: Firm-Level Evidence," in Elhanan Helpman, Dalia Marin and Thierry Verdier, eds., The Organization of Firms in a Global Economy, Cambridge, MA: Harvard University Press.

Haltiwanger, J.C., Jarmin, R.S. Miranda, J., (2013). "Who Creates Jobs? Small versus Large versus Young,” Review of Economics and Statistics, 95(2), 347-361.

Jarmin, R.S., (1999). "Evaluating the Impact of the Manufacturing Extension Partnership on Productivity Growth,” Journal of Policy Analysis and Management, 18(1), 99-119.

Jarmin R.S., and Miranda, J., (2002). “The Longitudinal Business Database,” Center for Economic Studies Working Papers, 02-17.

Kurz, C.J., and Senses, M., (2013). "Importing, Exporting and Firm Level Employment Volatility." Board of Governors of the Federal Reserve System Finance and Economics Discussion Series, 2013-44.

Lee, L.F., (1982). "Some Approaches to the Correction of Selectivity Bias," Review of Economic Studies, 49(3), 355-72.

Lipscomb, C.A., Youtie, J., Arora, S., Krause, A., and Shapira, P., (2015). "Evaluating the Long-Term Effect of NIST MEP Services on Establishment Performance” Center for Economic Studies Working Papers, 15-09. 
Maddala, G. S., (1983). Limited-Dependent and Qualitative Variables in Econometrics, New York: Cambridge University Press.

Melitz, M.J., (2003). "The Impact of Trade on Intra-Industry Reallocations and Aggregate Industry Productivity.” Econometrica, 71(6), 1695-1725.

Ordowich C., Cheney, D., Youtie, J., Fernández-Ribas, A., and Shapira, P., (2012). "Evaluating the Impact of MEP Services on Establishment Performance: A Preliminary Empirical Investigation," Center for Economic Studies Working Papers, 12-15.

Perkins S.M., Tu, W., Underhill, M.G, Zhou X.H., and Murray, M.D., (2000). "The use of propensity scores in pharmacoepidemiologic research.” Pharmacoepidemiol Drug Safety, 9(2), 93-101.

Roberts, M.J., and Tybout, J.R., (1997). "The Decision to Export in Colombia: An Empirical Model of Entry with Sunk Costs,” American Economic Review, 87(4), 545-64.

Tschetter, J.. (2010). “Exports Support American Jobs.” International Trade Research Report No. 1, U.S. Department of Commerce, International Trade Administration, Washington, DC.

Vannoorenberghe, G., (2012). "Firm-level Volatility and Exports,” Journal of International Economics, 86(1), 57-67.

White, H., (1980), "A Heteroskedasticity-Consistent Covariance Matrix Estimator and a Direct Test for Heteroskedasticity," Econometrica, 48(4), 817-838. 
Table 1. Select Means of GM Sample Compared to Universe

\begin{tabular}{|c|c|c|c|}
\hline & & GM & $\begin{array}{l}\text { Non- } \\
\text { GM }\end{array}$ \\
\hline \multirow[t]{2}{*}{ MNC (Related Party Trader) } & yes & $17 \%$ & $10 \%$ \\
\hline & No & $83 \%$ & $90 \%$ \\
\hline \multirow[t]{5}{*}{ Employment Size } & $1-10$ & $26 \%$ & $50 \%$ \\
\hline & $10-50$ & $39 \%$ & $33 \%$ \\
\hline & $50-100$ & $14 \%$ & $8 \%$ \\
\hline & $100-500$ & $15 \%$ & $7 \%$ \\
\hline & $500+$ & $6 \%$ & $2 \%$ \\
\hline \multirow[t]{3}{*}{ Firm Sector } & whole & $34 \%$ & $45 \%$ \\
\hline & retail & $5 \%$ & $18 \%$ \\
\hline & manuf & $62 \%$ & $37 \%$ \\
\hline \multirow[t]{3}{*}{ Firm Age } & 0 to 5 & $15 \%$ & $29 \%$ \\
\hline & 5 to 10 & $16 \%$ & $18 \%$ \\
\hline & 10 plus & $68 \%$ & $53 \%$ \\
\hline Mean Firm Age & & 16 & 11 \\
\hline $\begin{array}{l}\text { Mean Firm Age at first Contact } \\
\text { w/GM }\end{array}$ & & 15 & \\
\hline
\end{tabular}

Table 2. OLS Results

\begin{tabular}{|l|l|l|l|}
\hline Measure of Counseling & Outcome Measure & Estimate & StdErr \\
\hline \hline Counseling received in last 3 years? (Yes/No) & Annual Export Growth & $0.024^{*}$ & 0.002 \\
\# Counseling sessions (current year) & Annual Export Growth & $0.021^{*}$ & 0.001 \\
\# Counseling sessions last three years (t-2 to t) & Annual Export Growth & $0.005^{*}$ & 0.001 \\
& & & \\
Counseling received in last 3 years? (Yes/No) & Annual Employment Growth & $0.059^{*}$ & 0.004 \\
\# Counseling sessions (current year) & Annual Employment Growth & $0.025^{*}$ & 0.002 \\
\# Counseling sessions last three years (t-2 to t) & Annual Employment Growth & $0.010^{*}$ & 0.001 \\
\hline
\end{tabular}

$*$ indicates a statistically signific ant coefficient. 
Table 3. OLS: Small (<= 500 employees) vs. Large (> 500 employees) Firms

\begin{tabular}{|l|l|ll|ll|}
\hline & Outcome & \multicolumn{2}{l|}{$>\mathbf{5 0 0}$ Employ } & \multicolumn{2}{l|}{$<\mathbf{5 0 0}$ Employ } \\
Measure of Counseling & Measure & Est & StdErr & Est & StdErr \\
\hline \hline Counseling This Year (Yes/No) & Export Growth & $0.034^{*}$ & 0.015 & $0.021^{*}$ & 0.002 \\
\# Counseling Sessions (current year) & Export Growth & 0.009 & 0.007 & $0.021^{*}$ & 0.001 \\
\# Counseling Sessions (Current + Previous 2 Years) & Export Growth & 0.005 & 0.003 & $0.005^{*}$ & 0.001 \\
& & & & & \\
Counseling This Year (Yes/No) & Employ Growth & 0.006 & 0.007 & $0.057^{*}$ & 0.004 \\
\# Counseling Sessions (current year) & Employ Growth & 0.002 & 0.003 & $0.026^{*}$ & 0.002 \\
\# Counseling Sessions (Current + Previous 2 Years) & Employ Growth & 0.002 & 0.001 & $0.009^{*}$ & 0.001 \\
\hline
\end{tabular}

$*$ indicates a statistically signific ant coefficient.

Table 4. Fixed Effects Models

\begin{tabular}{|l|l|l|l|}
\hline Measure of Counseling & Outcome Measure & Estimate & StdErr \\
\hline \hline Counseling received in last 3 years? (Yes/No) & Annual Export Growth & $0.016^{*}$ & 0.003 \\
\# Counseling sessions (current year) & Annual Export Growth & $0.016^{*}$ & 0.002 \\
\# Counseling sessions last three years (t-2 to t) & Annual Export Growth & $0.003^{*}$ & 0.001 \\
& & & \\
Counseling received in last 3 years? (Yes/No) & Annual Employment Growth & 0.010 & 0.006 \\
\# Counseling sessions (current year) & Annual Employment Growth & 0.002 & 0.003 \\
\# Counseling sessions last three years (t-2 to t) & Annual Employment Growth & 0.002 & 0.001 \\
\hline
\end{tabular}

* indicates a statistically significant coefficient.

Table 5. Second Stage Regression Results from Maddala Model

\begin{tabular}{|l|l|l|l|}
\hline Measure of Counseling & Outcome Measure & Estimate & StdErr \\
\hline \hline Counseling received in last 3 years? (Yes/No) & Annual Export Growth & $0.023^{*}$ & 0.004 \\
& & & \\
Counseling received in last 3 years? (Yes/No) & Annual Employment Growth & $0.031^{*}$ & 0.002 \\
\hline
\end{tabular}

* indicates a statistic ally signific ant coefficient. 


\section{APPENDIX 1: Web Domain Names as Firm IDs}

Web sites offer a very simple and reliable way to link data sets. It is far easier to link Web site addresses than physical names and addresses. Web site addresses can be linked literally. Physical name and address matches rely on "fuzzy" algorithms that allow for multiple spellings and require a large number of iterations to capture all possible permutations. It is fairly easy to extract the core information from Web and e-mail addresses. Consider the following hypothetical examples:

\begin{tabular}{|l|l|l|l|l|}
\hline Observation ID \# & Firm Name & $\begin{array}{l}\text { BR Firm } \\
\text { ID \# }\end{array}$ & Reported Website & $\begin{array}{l}\text { Website- } \\
\text { based Firm } \\
\text { ID }\end{array}$ \\
\hline \hline 1 & Joe's Widget w orks & 101 & www.joeswidgets.com & joeswidgets \\
22 & Joe's Widget works & 101 & joeswidgets.org & joeswidgets \\
53 & Joe's Widget Annex & 222 & http://joeswidgets.com & joeswidgets \\
64 & Joe’s Widget works & 101 & joeswidgets.biz & joeswidgets \\
85 & Joe's Widget works & 101 & http://joeswidgets.com & joeswidgets \\
96 & Widget Annex & 432 & www.joeswidgets.com & joeswidgets \\
107 & Joe’s Widget works & 101 & joeswidgets.com & joeswidgets \\
\hline
\end{tabular}




\section{APPENDIX 2: Name and Address Matching Statistics}

Table A2-1 below reports the match rates between the observations/interactions in the organization file and Census' BR. My initial target was the same as that of Jarmin (1996): 70\% of the observations or better. My transaction match rate was slightly below this overall (64\%) and for U.S. owned-firms $(66 \%) .^{20}$

Table A2-1. Overall Match Rates

\begin{tabular}{|c|c|c|c|c|c|}
\hline & $\begin{array}{l}\text { Number of } \\
\text { Interactions }\end{array}$ & $\begin{array}{l}\text { Percent of } \\
\text { Interactions } \\
\text { Matched To } \\
\text { BR }\end{array}$ & $\begin{array}{l}\text { Percent of } \\
\text { Matched } \\
\text { Interactions } \\
\text { with GM } \\
\text { FirmID }\end{array}$ & $\begin{array}{l}\text { Number of } \\
\text { Matched } \\
\text { GM } \\
\text { FirmIDs }\end{array}$ & $\begin{array}{l}\text { Number of } \\
\text { Unmatched } \\
\text { GM } \\
\text { FirmIDs }\end{array}$ \\
\hline $\begin{array}{l}\text { All } \\
\text { Matches }\end{array}$ & 227.782 & $64 \%$ & $85 \%$ & 106,529 & 51,078 \\
\hline
\end{tabular}

Table A2-2, as well as the results that follow, also report the share of matched interactions that have GM_IDs since these would be the usable set of observations. In separate results, I also compared the number of GM_IDs to the number of BR_IDs. If the BR indicated that the matched observations contained 100 unique firms but the GM_IDs indicated there were only 10, it would indicate that one of them was inaccurate. It is far more likely that they are measuring the same types of entities if the counts roughly agree - and I found that they do. Finally, I also report the number of unmatched GM_IDs.

Table A2-2 below provides a count of the matches made in each type of pass through the data. It shows that the name and address matching accounted for the great majority of matches between the sources, although name and zip code was also important. The share of matches with GM_IDs is fairly constant across match type.

Table A2-2. Percent of Total Matches Achieved by Matching Type

\begin{tabular}{lrcr}
\hline & $\begin{array}{l}\text { Number of } \\
\text { Interactions }\end{array}$ & $\begin{array}{l}\text { Percent of Matched } \\
\text { Interactions with } \\
\text { GM FirmID }\end{array}$ & $\begin{array}{l}\text { Number of } \\
\text { Matched GM } \\
\text { FirmIDs }\end{array}$ \\
\hline Name \& Address & 106,596 & 86.64 & 78,002 \\
Name \& Zip Code & 26,645 & 80.63 & 17,451 \\
Name \& City & 835 & 74.25 & 419 \\
Name \& State & 10,749 & 74.46 & 6,113 \\
\hline Total & 144,825 & 84.56 & 101,985 \\
\hline
\end{tabular}

Match rates are slightly below the target of 70\%. How ever, this does not factor in the loss from the lack of GM_IDs on all observations. Recall that I only have GM_IDs on about 85\% of the observations. While I match roughly $64 \%$ of the interactions in the organization database, only $85 \%$ of these have GM_IDs, for an effective match rate of about $54 \%$.

\footnotetext{
${ }^{20}$ In all results, I condition on firms ' having U.S. addresses but allow for foreign ownership per instructions from the GM programrepres entative.
} 
If there are no clear patterns among the matches and non-matches across observable characteristics then the low match rate is less likely to be a serious issue. Tables A2-3 through A2-6 benchmark the match rates across several key firm characteristics. For example, Table A2-3 shows the match rates by firm industry. Note that a large share of the firms is not engaged in goods-trading activities (manufacturing, wholesale, and retail). One of the major metric so this study is exporting, and I can only measure exports of goods, not services.

Table A2-3. Match Rate by Industry

\begin{tabular}{|c|c|c|c|c|c|}
\hline GM Industry & $\begin{array}{l}\text { Number } \\
\text { of Inter- } \\
\text { actions }\end{array}$ & $\begin{array}{l}\text { Percent of } \\
\text { Inter- } \\
\text { actions } \\
\text { Matched } \\
\text { To BR }\end{array}$ & $\begin{array}{l}\text { Percent of } \\
\text { Matched } \\
\text { Inter- } \\
\text { actions } \\
\text { with GM } \\
\text { FirmID }\end{array}$ & $\begin{array}{l}\text { Number } \\
\text { of } \\
\text { Matched } \\
\text { GM } \\
\text { FirmIDs }\end{array}$ & $\begin{array}{l}\text { Number } \\
\text { of Missed } \\
\text { GM } \\
\text { FirmIDs }\end{array}$ \\
\hline Agriculture, & 1189 & 63 & 77 & 566 & 286 \\
\hline Mining, Oil and Gas & 5778 & 66 & 85 & 3106 & 1390 \\
\hline Manufacturing & 76921 & 71 & 85 & 42957 & 14223 \\
\hline Wholesale and Retail & 21806 & 73 & 81 & 12289 & 4084 \\
\hline FIRE & 41959 & 67 & 87 & 22512 & 9726 \\
\hline Education, Health Care & 4338 & 71 & 92 & 2601 & 926 \\
\hline Arts, Entertainment & 1944 & 70 & 90 & 1134 & 483 \\
\hline Other Services & 3756 & 72 & 83 & 2220 & 782 \\
\hline Public Administration & 3877 & 49 & 80 & 1356 & 1050 \\
\hline No NAICS Code & 66214 & 49 & 83 & 23567 & 19629 \\
\hline Total & 227782 & 64 & 85 & 112308 & 52579 \\
\hline
\end{tabular}

Next, I look at the size distribution of the matches using both employment (Table A2-4) and revenue (Table A2-5) categories as metrics. The match rates are lowest for the smallest firms and those of unknown size. The match rates for these categories are $50 \%$ or less while the other size categories are $70 \%$ or more. It is unclear what the "unknown" size category is capturing, which makes it hard to determine if the low match rate is a problem. The lower match rate for small firms is not completely unexpected but is of some concern. 
Table A2-4. Match Rate by GM Employment Category

\begin{tabular}{|c|c|c|c|c|c|}
\hline $\begin{array}{l}\text { Employment } \\
\text { Category }\end{array}$ & $\begin{array}{l}\text { Number of } \\
\text { Interactions }\end{array}$ & $\begin{array}{l}\text { Percent of } \\
\text { Interactions } \\
\text { Matched To } \\
\text { BR }\end{array}$ & $\begin{array}{l}\text { Percent of } \\
\text { Matched } \\
\text { Interactions } \\
\text { with GM } \\
\text { FirmID }\end{array}$ & $\begin{array}{l}\text { Number of } \\
\text { Matched } \\
\text { GM } \\
\text { FirmIDs }\end{array}$ & $\begin{array}{l}\text { Number of } \\
\text { Unmatched } \\
\text { GM } \\
\text { FirmIDs }\end{array}$ \\
\hline$<5$ & 44370 & 56 & 76 & 17842 & 12456 \\
\hline 5-9 & 19770 & 75 & 83 & 12026 & 3878 \\
\hline 10-19 & 19441 & 82 & 86 & 13348 & 2876 \\
\hline $20-49$ & 22776 & 86 & 88 & 16856 & 2704 \\
\hline 50-99 & 13083 & 85 & 90 & 9882 & 1567 \\
\hline $100-499$ & 15947 & 85 & 91 & 11988 & 1895 \\
\hline 500-999 & 2913 & 84 & 92 & 2186 & 408 \\
\hline $1000+$ & 4954 & 79 & 94 & 3263 & 779 \\
\hline Unknown & 84528 & 46 & 83 & 27218 & 26492 \\
\hline
\end{tabular}

Table A2-5. Match Rate by Revenues Category

\begin{tabular}{|c|c|c|c|c|c|}
\hline Revenues & $\begin{array}{l}\text { Number of } \\
\text { Transaction }\end{array}$ & $\begin{array}{l}\text { Percent of } \\
\text { Transaction } \\
\text { Matched To } \\
\text { BR }\end{array}$ & $\begin{array}{l}\text { Percent of } \\
\text { Matched } \\
\text { Transaction } \\
\text { with GM } \\
\text { FirmID }\end{array}$ & $\begin{array}{l}\text { Number of } \\
\text { Matched } \\
\text { GM } \\
\text { FirmIDs }\end{array}$ & $\begin{array}{l}\text { Number of } \\
\text { Unmatched } \\
\text { GM } \\
\text { FirmIDs }\end{array}$ \\
\hline$<500 \mathrm{~K}$ & 62002 & 68 & 82 & 32,755 & 13,041 \\
\hline $500 \mathrm{~K}-1 \mathrm{M}$ & 14361 & 79 & 82 & 9,086 & 2,286 \\
\hline $1 \mathrm{M}-100 \mathrm{M}$ & 44141 & 88 & 88 & 33,202 & 4,199 \\
\hline $100-250 \mathrm{M}$ & 1201 & 88 & 93 & 978 & 1,118 \\
\hline$>250 \mathrm{M}$ & 2199 & 84 & 95 & 1,631 & 273 \\
\hline Unknown & 103878 & 47 & 84 & 35,035 & 31,721 \\
\hline Total & 227782 & 64 & 85 & 112687 & 51738 \\
\hline
\end{tabular}

The most basic way to measure treatment is by whether or not the firm contacted GM. However, this is a very liberal definition and it is very unlikely that firms could benefit just from making contact with GM. Ideally, one would like to measure the amount and intensity of the services provided. One way to do that is with the "Is Counseling" variable, which indicates whether an interaction was considered counseling. The match rates for this are shown in Table A2-6.

Table A2-6. Counseling as Treatment

\begin{tabular}{|c|c|c|c|c|c|}
\hline $\begin{array}{l}\text { Is } \\
\text { Counseling? }\end{array}$ & $\begin{array}{l}\text { Number of } \\
\text { Interactions }\end{array}$ & $\begin{array}{l}\text { Percent of } \\
\text { Interactions } \\
\text { Matched To BR }\end{array}$ & $\begin{array}{l}\text { Percent of } \\
\text { Matched } \\
\text { Interactions with } \\
\text { GM FirmID }\end{array}$ & $\begin{array}{l}\text { Number of } \\
\text { Matched GM } \\
\text { FirmIDs }\end{array}$ & $\begin{array}{l}\text { Number of } \\
\text { Unmatched GM } \\
\text { FirmIDs }\end{array}$ \\
\hline No & 111,486 & $73 \%$ & $95 \%$ & 12,248 & 4,912 \\
\hline Yes & 344,594 & $74 \%$ & $95 \%$ & 43,579 & 17,132 \\
\hline
\end{tabular}


The sample size is larger for this variable because there is a record of it for all GM interactions with their clients. This may allow us to measure the intensity of treatment by summing the number of counseling sessions a firm receives. 
APPENDIX 3: Full Regression Results

Table A3-1. First Stage Results of 2-Step Model

\begin{tabular}{|l|ll|}
\hline & & \multicolumn{3}{|c|}{ Standard } \\
Parameter & Estimate & Error \\
\hline \hline Intercept & $-1.475^{*}$ & 0.008 \\
age_cat 1 0 to 5 & $-0.290^{*}$ & 0.004 \\
age_cat 2 5 to 10 & $-0.105^{*}$ & 0.004 \\
age_cat $\mathbf{3} \mathbf{1 0}$ plus & 0.000 &. \\
mnc 0 & $-0.686^{*}$ & 0.006 \\
mnc 1 & 0.000 &. \\
sector 1 whole & $-0.271^{*}$ & 0.000 \\
sector 2 retail & $-0.972^{*}$ & 0.005 \\
sector 3 manuf & 0.000 &. \\
year 2002 & $-0.406^{*}$ & 0.009 \\
year 2003 & $-0.186^{*}$ & 0.008 \\
year 2004 & $-0.039^{*}$ & 0.007 \\
year 2005 & 0.011 & 0.007 \\
year 2006 & $0.033^{*}$ & 0.007 \\
year 2007 & $0.038^{*}$ & 0.007 \\
year 2008 & 0.013 & 0.007 \\
year 2009 & 0.005 & 0.007 \\
year 2010 & $-0.015^{*}$ & 0.007 \\
year 2011 & 0.000 &. \\
distance & $-0.036^{*}$ & 0.004 \\
Rho & 0.000 & 0.029 \\
\hline
\end{tabular}

* indicates a statistically signific ant coefficient. 
Table A3-2. Second Stage Results of 2-Step Models

\begin{tabular}{|l|ll|ll|}
\hline \multirow{2}{*}{ Variable } & \multicolumn{2}{|l|}{ Export Growth } & \multicolumn{2}{l|}{ Employment Growth } \\
\cline { 2 - 5 } & Parameter & Standard & Parameter & Standard \\
\hline \hline Intercept & $0.063^{*}$ & 0.022 & $-1.159^{*}$ & 0.042 \\
age1 & $0.032^{*}$ & 0.002 & $0.221^{*}$ & 0.005 \\
age2 & $0.003^{*}$ & 0.001 & $-0.075^{*}$ & 0.002 \\
mnc & $0.414^{*}$ & 0.006 & $0.435^{*}$ & 0.010 \\
retail & $0.027^{*}$ & 0.008 & $-0.367^{*}$ & 0.015 \\
whole & $0.007^{*}$ & 0.002 & $-0.082^{*}$ & 0.004 \\
yr02 & 0.002 & 0.003 & $0.028^{*}$ & 0.006 \\
yr03 & $-0.011^{*}$ & 0.002 & $-0.072^{*}$ & 0.003 \\
yr04 & $-0.004^{*}$ & 0.001 & $-0.005^{*}$ & 0.001 \\
yr05 & $-0.009^{*}$ & 0.001 & -0.001 & 0.001 \\
yr06 & $-0.008^{*}$ & 0.001 & $0.002^{*}$ & 0.001 \\
yr07 & $-0.002^{*}$ & 0.001 & $0.011^{*}$ & 0.001 \\
yr08 & $-0.002^{*}$ & 0.001 & $-0.025^{*}$ & 0.001 \\
yr09 & $-0.041^{*}$ & 0.001 & $-0.100^{*}$ & 0.001 \\
yr10 & $0.004^{*}$ & 0.001 & $-0.045^{*}$ & 0.001 \\
counsel_dum & $0.025^{*}$ & 0.004 & $0.058^{*}$ & 0.002 \\
Mills & $-0.027^{*}$ & 0.009 & $0.405^{*}$ & 0.017 \\
\hline
\end{tabular}

* indicates a statistically signific ant coefficient. 